\title{
Structural studies on the antimicrobial peptide Brevinin 1E by spectroscopic methods
}

\author{
Woo-Sung Son, Ji-Sun Kim, Hyung-Eun Kim, Sang-Ho Park and Bong-Jin Lee* \\ Research Institute of Pharmaceutical Sciences, College of Pharmacy, Seoul National University, \\ San 56-1, Shillim-dong, Gwanak-gu, Seoul 151-742, South Korea
}

\begin{abstract}
Skin extracts of frogs are a rich source of pharmacologically active peptides such as caeruleins, tachykinins, bradykinins, thyrotropin-releasing hormone, bombesin-like and opioid peptides. A large variety of antimicrobial peptides has been isolated from Rana species. These peptides, grouped in several families on the basis of differing length and distinct activity, were found to have one structural motif in common: an intramolecular disulfide bridge located at the C-terminal end, forming a seven-member ring, which was designated 'Rana box'. Brevinin 1E is a 24-residue antimicrobial peptide isolated from the skin of a frog, Rana brevipoda. This peptide shows a broad range of antimicrobial activity against prokaryotic cells but shows very much hemolytic activity against human red blood cells. The solution structure of Brevinin $1 \mathrm{E}$ was studied by using CD (circular dichroism) and NMR (nuclear magnetic resonance) spectroscopy. CD investigation revealed that Brevinin $1 \mathrm{E}$ adopts random structure in aqueous solution but adopts mainly $\alpha$-helical structure in TFE/water $(6: 4, \mathrm{v} / \mathrm{v})$ solution. The three-dimensional structure of Brevinin 1E was determined in 60\% TFE/water solution using homonuclear NMR spectroscopy. This peptide showed mainly an $\alpha$-helical structure with amphipathic property. Its three-dimensional structure is similar to those of other peptides such as magainin, nigrocin and ranalexin. Therefore, Brevinin $1 \mathrm{E}$ can be classified into the family of antimicrobial peptides containing a single linear $\alpha$-helix that interact with target microbial membrane, leading to cell death through disruption of membrane integrity.
\end{abstract}

\section{Introduction}

The history of antimicrobial peptides runs in parallel with the penicillin work. It starts in 1939 with Dubos' demonstration that 'an unidentified soil bacillus' produced some antimicrobial compounds that could prevent pneumococcal infections in mice. The year after, Hotchkiss and Dubos reported a partial purification of the bactericidal substances produced by this soil bacterium, now identified as Bacillus brevis. Then, in 1941-1942, they described how, starting from a B. brevis culture, they had purified and crystallized tyrocidine and gramicidin and shown them to be composed of amino acids, some of them D-amino acids. Both these antibacterial peptides turned out to be more or less toxic; tyrocidine to the extent that it could never be used to treat an infection. However, before penicillin became available, gramicidin was to a limited extent used as a therapeutic agent $[7,9]$.

Ever since magainin was discovered from African clawed frog, Xenopus laevis, quite a number of antimicrobial peptides were discovered subsequently in other frog species such as Ranidae [10]. In 19921994, for example, a novel family of antimicrobial peptides, brevinins [33,37], esculentins [34], ranalexin [13], and gaegurins [25] have been detected in the skin of Rana brevipoda, Rana esculenta, Rana catesbeiana, and Rana rugosa, frogs of the family of Ranidae, respectively. These peptides are characterized

\footnotetext{
*Corresponding author. Tel.: +82 2880 7869; Fax: +82 2872 3632; E-mail: lbj@nmr.snu.ac.kr
} 
by the presence of two cysteine residues in positions 1 and 7 as counted from the carboxyl terminus. These peptides consist of 20-46 residues in length and adopt one or two amphipathic $\alpha$-helical structures.

From the extensive studies on structure-function relationship of these peptides, the mechanism of antimicrobial activity has been proposed: Electrostatic interactions between the lysines and the negatively charged phospholipid head group of the target cell promote binding to and accumulation of the helical peptide on the outer leaflet of the membrane. The bound peptide lies on the membrane with its long helix axis parallel to membrane surface. At low concentrations, the peptide adsorbs to the membrane as a monomer. At higher concentrations, the membrane-bound peptide begins to self-aggregate and equilibrates with a multimeric water-filled pore (two to six monomers in a rosette) in which the hydrophilic residues of the individual monomers face inward and the apolar residues interact with the acyl chains of the lipids. This transition occurs at roughly the same critical concentration required for cytotoxic activity, implying that the peptide insertion into the membrane is responsible for cytotoxicity. A transmembrane electric potential, negative inside, enhances the pore-forming activity of the peptide favoring insertion by interacting with the permanent dipole moment of the peptide that is oriented along the long axis of the helix. The solvent-filled unspecific pores, by permeating the membrane to various substances including ions, cause the electric potential to dissipate across the membrane, leading to death of the microbial cell. Although these models explain the permeating effect of helical antimicrobial peptides, they do not account for their remarkable specificity of action, which may be partly explained by the difference in lipid composition of the membrane of the target cells and the exact nature of the peptide's side chains.

For animals, these antimicrobial peptides serve as immune substances and they are primary defense agents of innate immunity rather than secondary metabolites $[23,40]$. Their potential use as drugs is motivated in part by the increasing spread of bacterial resistance to conventional antibiotics, in part because endogenous antibiotics may offer a new avenue to the therapy of infectious diseases [19]. The elucidation of the structure-activity relationship of antimicrobial peptides is the key step for the development of a new peptide antibiotics.

Up to the present the structures of the many amphibian antimicrobial peptides have been determined $[14,18,22,24,26,42,43]$. Among these peptides, magainin is the representative antimicrobial peptide, which has been extensively studied by solution and solid-state NMR spectroscopy [3-6,11,12,24,29, 46]. Magainin adopts a single amphipathic helix and is known to interact directly with bacterial cell membrane and to destroy the ionic gradient across the cell membrane by forming ion channels [46]. Among the peptides isolated from Ranidae, the structures of ranalexin have been also determined and the mechanism of activity of these peptides is known to be similar to that of magainin $[14,35]$.

In this study, the solution structures of Brevinin 1E, a 24-residue antimicrobial peptide, were determined in $60 \%$ trifluoroethanol solution by using NMR to investigate the structure-activity relationship.

\section{Materials and methods}

\subsection{Materials}

2,2,2-Trifuoroethanol- $d_{3}\left(99.5 \%, d_{3}\right.$-TFE) was purchased from Aldrich. 99.95\% $\mathrm{D}_{2} \mathrm{O}$ was obtained from Sigma and Sephadex G-50 and carboxymethyl-Sepharose CL-6B were purchased from Amersham Pharmacia. All other chemicals were of analytical grade obtained from various manufacturers. 


\begin{tabular}{|c|c|c|}
\hline & 10 & 20 \\
\hline Brevinin-1 & FLPVLAGIAAKVVPALF & $\mathrm{CK} \mathrm{I} \mathrm{TKKC}$ \\
\hline Brevinin- $1 \mathrm{E}$ & I: I, PII,AGI,AAN I: I,PK IF & $\mathrm{CKITRC}$ \\
\hline Brevinin-1 Ea & $F L P \wedge I F R M \wedge \wedge K V V P T I I$ & CS I TKKC \\
\hline Brevinin- $I \mathrm{~Eb}$ & VIPFVASVAAEMMQHVY & AASRKC \\
\hline Brevinin-1 Ec & I:I,PI, I AGI, AANI: I:PK I F & KITRKC \\
\hline Ranalexin & I: I GGL I K I VPAM I PK I I: & $\mathrm{CKITRKC}$ \\
\hline Nigrocin 2 & $\sim \sim G L L S K V \sim L G V G K K V L$ & CGVSGLC \\
\hline Gaegurin 5 & FI,GAI.FKVASKVI,PSVK & A I TKKC \\
\hline Gaegurin 6 & F LPLLAGLAANF LPT I I & CF I SYKC \\
\hline
\end{tabular}

Fig. 1. Sequences of Brevinin 1E and sequence alignment with other antimicrobial peptides from Ranidae. The boxed region indicates the 'Rana box' existed in Ranidae.

\subsection{Sample preparation}

The synthetic peptide with a disulfide bridge between $\mathrm{C} 18$ and $\mathrm{C} 24$, corresponding to the amino acid sequence of Brevinin 1E (Fig. 1), was purchased from AnyGen, Co., Ltd., South Korea, and used for further analysis. The sequence and purity of the synthetic peptide were confirmed by mass spectroscopy and HPLC.

\subsection{Minimal inhibitory concentration and hemolytic activity}

The standard assay of an antimicrobial activity was measured as described previously [25]. Bacterial cells were grown overnight in Luria-Bertani (LB) media and inoculated into $5 \mathrm{ml}$ of molten $0.6 \% \mathrm{LB}$ agar with final $10^{7}$ colony forming units $(\mathrm{CFU}) / \mathrm{ml}$, which was overlaid on a $150 \mathrm{~mm}$ Petri dish containing solidified 2\% LB agar. After the top agar hardened, 3-10 $\mu$ l of peptide samples were dropped into the 3-mm wells on the surface of the top agar and completely dried before incubating overnight at $37^{\circ} \mathrm{C}$. Antimicrobial activity was determined by observing the zone of suppression of bacterial growth around the 3-mm wells. Minimal inhibitory concentrations (MIC) against various bacteria were determined by incubating $10^{6} \mathrm{CFU} / \mathrm{ml}$ of cells in LB media including variable amount of peptides. Cell growth was quantified by measuring $\mathrm{OD}_{600}$ of the culture suspension.

Hemolysis induced by Brevinin 1E was determined by incubating a $10 \%(\mathrm{v} / \mathrm{v})$ suspension of human red blood cells $(\mathrm{RBC})$ in phosphate-buffered saline with the appropriate amount of Brevinin $1 \mathrm{E}$ at $37^{\circ} \mathrm{C}$ for $10 \mathrm{~min}$. After centrifugation at $10,000 \times g$ for $10 \mathrm{~min}$, the optical density at $350 \mathrm{~nm}$ of the supernatant was measured. The relative optical density was compared to that of the suspension treated with $0.1 \%$ Triton X-100 defined \% hemolysis.

\subsection{Circular dichroism (CD) spectroscopy}

Circular dichroism (CD) spectra were obtained on a JASCO J-715 spectropolarimeter to investigate the secondary structure of Brevinin 1E. Samples were prepared by dissolving the peptide to the concentration of $50 \mu \mathrm{M}$ in various solvents: aqueous solution, TFE/water $(7: 3,6: 4,5: 5,4: 6,3: 7$, and $2: 8$ $\mathrm{v} / \mathrm{v}, \mathrm{pH} 4.0)$ solutions and $5 \mathrm{mM}$ dodecylphosphocholine (DPC) $(\mathrm{pH} 4.0)$. The spectra were measured between 190 and $250 \mathrm{~nm}$. Three consecutive scans per sample were performed in a $2 \mathrm{~mm}$ cell at $20^{\circ} \mathrm{C}$. Three scans were added and averaged, followed by subtraction of the CD signal of the solvent. The helicity of the peptides was estimated from the mean residue ellipticity at $222 \mathrm{~nm}$ [47]. 


\subsection{Nuclear magnetic resonance (NMR) spectroscopy}

Samples for NMR measurements were prepared as $2.5 \mathrm{mM}$ peptide in $d_{3}$-TFE/water $(6: 4, \mathrm{v} / \mathrm{v}), \mathrm{pH} 3.0$. Data acquisitions for the homonuclear double quantum filtered correlation spectroscopy (DQF-COSY), total correlation spectroscopy (TOCSY), and nuclear Overhauser effect spectroscopy (NOESY) spectra of Brevinin 1E were carried out at $40^{\circ} \mathrm{C}$ on Bruker DRX-500 and DRX-600 spectrometers equipped with a gradient unit. All NMR spectra were acquired using the TPPI method. Data matrices contained $4000 \times$ 512 points and 64 scans were accumulated. Two-dimensional (2D) TOCSY spectra were acquired with a mixing time of $60 \mathrm{~ms}$. 2D NOESY spectra were acquired with mixing times of 200, 250, and $300 \mathrm{ms,}$ respectively. For detecting the $\alpha \mathrm{H}$ protons resonating at the same frequency as water, the WATERGATE sequence [31] was used to suppress the solvent signals in the NOESY experiments. Assignment of spinsystems to individual amino acids was achieved using DQF-COSY and TOCSY spectra, while complete resonance assignment was obtained by the combined use of TOCSY and NOESY spectra, following the sequential assignment strategy [28]. The amide proton exchange experiments were carried out in $d_{3}$-TFE $/ \mathrm{D}_{2} \mathrm{O}(6: 4, \mathrm{v} / \mathrm{v})$ at $40^{\circ} \mathrm{C}$. All NMR spectra were processed by using NMRPipe [15] software package and were analyzed with the NMRView program in Linux machine (RedHat 7.1). The NOESY spectra of Brevinin $1 \mathrm{E}$ in TFE/water solution obtained at $40^{\circ} \mathrm{C}$ were used for volume measurement of the NOE cross-peaks. Chemical shifts were referenced to methyl signals of sodium 4,4-dimethyl-4-silapentane-1sulfonate.

\subsection{Structure calculation}

Distance restraints were obtained from the homonuclear and NOESY spectra with $200 \mathrm{~ms}$ mixing times. Comparisons were made to the 200 and $300 \mathrm{~ms}$ NOESY spectra to assess possible contributions from spin diffusion. All NOE data were classified into three classes, strong, medium, and weak, corresponding to upper bound interproton distance restraints of 3.0, 4.0, and 5.0 $\AA$, respectively. Lower distance bounds were taken as the sum of the van der Waals radii of $1.8 \AA$. As no stereospecific assignment could be made for the methyl and methylene protons, appropriate pseudoatom corrections were applied [27]. To generate the structures of Brevinin 1E, a total of 291 distance restraints and 15 backbone dihedral angle restraints, which is inferred from DQF-COSY experiments, were used. Three additional restraints were added to define the disulfide bridge between Cys18 and Cys24. The target values of $\mathrm{S}(18)-$ $\mathrm{S}(24), \mathrm{S}(18)-\mathrm{C}_{\beta}(24)$, and $\mathrm{S}(24)-\mathrm{C}_{\beta}(18)$ were set to $2.20( \pm 0.02) \AA, 2.99( \pm 0.5) \AA$, and $2.99( \pm 0.5) \AA$, respectively [30]. Three-dimensional structures were calculated by using the simulated annealing and energy minimization protocol in the program CNS1.1 [2] and Aria1.1. The structures were analyzed by PROCHECK3.5.4 [39] and MOLMOL. All structure figures were generated with MOLMOL and CHIMERA.

\section{Results and discussion}

\subsection{Primary structures of Brevinin $1 E$}

Brevinin 1E has two conserved cysteines delineated by a disulfide bridge in the $\mathrm{C}$-terminal region (rana box), which is characteristic of the antimicrobial peptides from Ranidae. The sequence homology between Brevinin 1E and other peptides from Ranidae is high (Fig. 1). The starting N-terminal residues of Brevinin1E are similar to those of relatively short (20-24 residue long) antimicrobial peptides from 
Table 1

Antimicrobial activities of Brevinin 1E against various microorganisms

\begin{tabular}{lc}
\hline Microorganism & $\begin{array}{c}\text { MIC }(\mu \mathrm{g} / \mathrm{ml}) \\
\text { Brevinin IE }\end{array}$ \\
\hline Gram-positive bacteria & 6.3 \\
Bacillus subtilis ATCC 663 & 6.3 \\
Micrococcus luteus ATCC 10240 & 6.3 \\
Staphylococcus aureus ATCC 6538p & \\
Gram-negative bacteria & 12.5 \\
Escherichia coli ATCC 25922 & 25 \\
Shigella dysentariae ATCC 9752 & 100 \\
Salmonella typhimurium ATCC 14028 & 25 \\
Citrobacter freundii ATCC 6750 & 12.5 \\
Klebsiella pneumoniae ATCC 10031 & $>200$ \\
Serratia marcescens ATCC 271 17 & $>200$ \\
Proteus mirabilis ATCC 25933 & 100 \\
Pseudomonas aeruginosa ATCC 27853 & \\
\hline
\end{tabular}

Table 2

Hemolytic activity of Brevinin IE against human red blood cells

\begin{tabular}{cc}
\hline Concentration $(\mu \mathrm{g} / \mathrm{ml})$ & $\begin{array}{c}\text { Hemolysis of human red blood cells }(\%) \\
\text { Brevinin IE }\end{array}$ \\
\hline 0 & 0 \\
25 & 25.8 \\
50 & 47.38 \\
100 & 189.21 \\
\hline
\end{tabular}

Ranidae. These highly conserved two N-terminal residues (F1 and L2) are known to be involved in the peptide-micelle interaction due to their strong hydrophobicity [14]. Brevinin 1E has two proline residues, which are highly conserved in the antimicrobial peptides from Ranidae. These residues are known to be essential for antimicrobial activity [26]. From these views, Brevinin 1E has a similar primary structural characteristic compared with other antimicrobial peptides from Ranidae.

\subsection{Minimal inhibitory concentration and hemolytic activity}

The antimicrobial spectra of Brevinin 1E were determined by measuring the MIC. Table 1 shows the MIC values of Brevinin 1E against various bacteria. Gram-positive bacteria showed especially high sensitivity to this peptide. Gram-negative bacteria showed different sensitivity to peptides in accordance with each bacterial species. Brevinin 1E showed good activities in the MIC value of $12.5 \mu \mathrm{g} / \mathrm{ml}$ against the Gram-negative bacteria, Escherichia coli and Klebsiella pneumoniae, and they were moderately active against Shigella dysentariae and Citrobacter freundii whereas they were poorly active against Salmonella typhimurium, Pseudomonas aeruginosa and had no effect on Serratia marcescens and Proteus mirabilis.

In a conventional assay on human RBC, Brevinin $1 \mathrm{E}$ exhibited severe hemolytic activity. Addition of Brevinin 1E to human RBC up to $100 \mu \mathrm{g} / \mathrm{ml}$ causes severe hemolysis (Table 2). Brevinin 1E has been known to exhibit much hemolytic activity unlike many other antimicrobial peptides from Ranidae [34, $35]$. In the case of the derivative of Brevinin $1 \mathrm{E}$, the elimination of the intra-disulfide bridge did not decrease the antimicrobial activity but did decrease the hemolytic activity [35]. And it was known that 


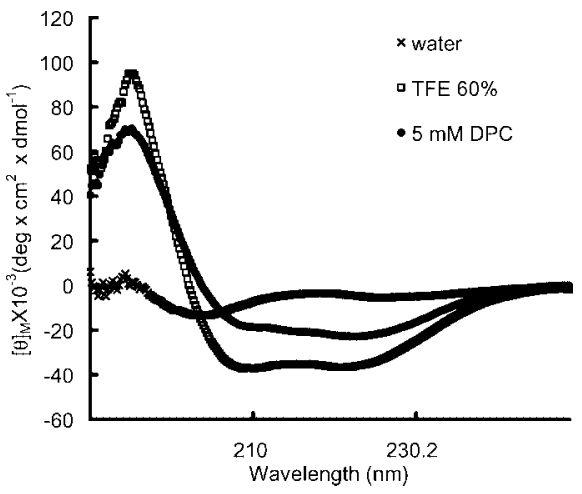

Fig. 2. CD spectra of Brevinin 1E in aqueous solution $(\times)$, in $60 \%$ TFE/water solution $(\square)$, in $5 \mathrm{mM} \mathrm{DPC} \mathrm{( \bullet ).}$

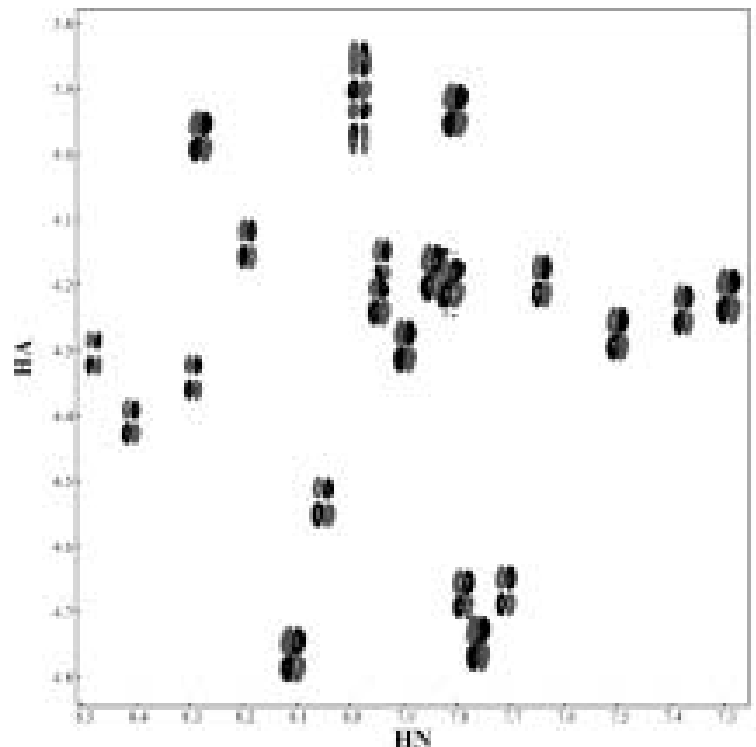

HN

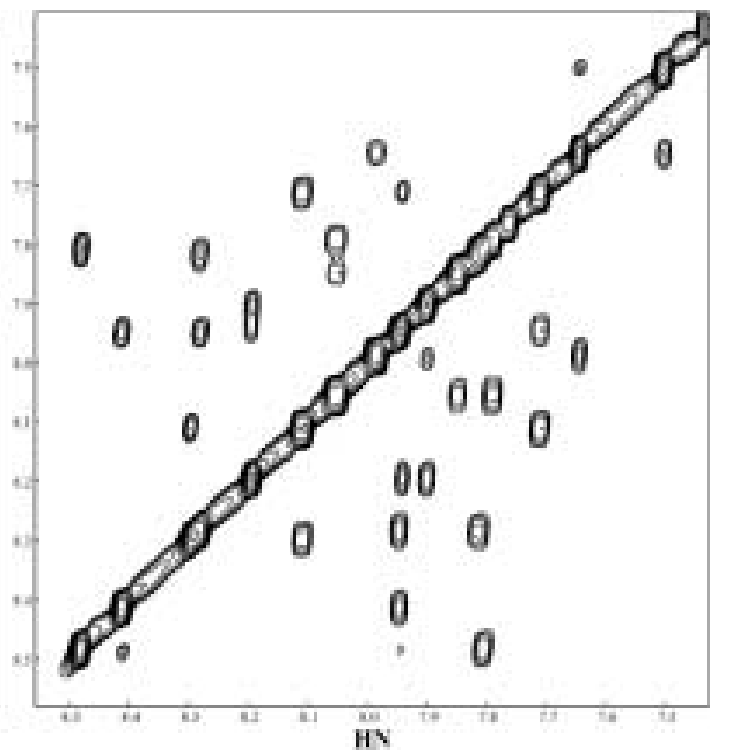

HY

Fig. 3. DQF-COSY (left) and NOESY (right) spectra of Brevinin 1E. NMR measurements were fulfilled using Burker DRX $(600 \mathrm{MHz})$ in $60 \% d_{3}-\mathrm{TFE} /$ water, $\mathrm{pH} 3.0,313 \mathrm{~K}$.

the appearance of numerous contiguous apolar residues in a helix is necessary for a significant hemolysis to occur [38]. Brevinin 1E has more apolar residues in N-terminal helix than other antimicrobial peptides from Ranidae. Therefore, it is suggested that the hydrophobic nature of the intra-disulfide bridge and apolar residues in a helix are important for the strong hemolytic activity [35].

\subsection{Secondary structure}

Many membrane peptides and proteins are insoluble in water, which make it difficult to study the solution structure by using NMR spectroscopy. Brevinin 1E is highly soluble, despite of forming the unordered structure, in water. It has been reported that several membrane peptides such as magainin and ranalexin are also soluble in water and their structures in TFE/water solution are similar to those in DPC micelles $[14,24]$. In many cases, TFE has been used as helix-promoting solvent, since it induces 
Table 3

${ }^{1} \mathrm{H}$ resonance assignment of Brevinin IE in 60\% $d_{3}$-TFE/water solution, $\mathrm{pH} 3.0,313 \mathrm{~K}$

\begin{tabular}{|c|c|c|c|c|c|}
\hline & $\mathrm{H}^{\mathrm{N}}$ & $\mathrm{H}^{\alpha}$ & $\mathrm{H}^{\beta}$ & $\overline{\mathrm{H}^{\gamma}}$ & Others \\
\hline Phe1 & n.d. $^{\text {a }}$ & 4.329 & n.d. ${ }^{\mathrm{a}}$ & n.d. $^{\text {a }}$ & n.d. $^{\text {a }}$ \\
\hline Leu2 & 7.759 & 4.747 & 1.623 & 1.623 & $\mathrm{H}^{\delta} 0.987$ \\
\hline Pro3 & & 4.462 & $2.350 / 2.080$ & 2.104 & $\mathrm{H}^{\delta} 3.826 / 3.567$ \\
\hline Leu4 & 7.377 & 4.238 & 1,698 & 1.698 & $\mathrm{H}^{\delta} 0.988$ \\
\hline Leu5 & 7.500 & 4.277 & 1.747 & 1.747 & $\mathrm{H}^{\delta} 1.020 / 0.976$ \\
\hline Ala6 & 7.641 & 4.197 & 1.539 & & \\
\hline Gly7 & 7.984 & $3.959 / 3.879$ & & & \\
\hline Leu8 & 7.900 & 4.297 & $1.938 / 1.848$ & 1.733 & $\mathrm{H}^{\delta} 0.962$ \\
\hline Ala9 & 8.193 & 4.139 & 1.554 & & \\
\hline Ala10 & 7.942 & 4.169 & 1.544 & & \\
\hline Asn11 & 7.710 & 4.668 & $2.777 / 2.647$ & & $\mathrm{HN}^{\gamma} 7.140 / 6.592$ \\
\hline Phe12 & 8.108 & 4.766 & 3.209 & & $\mathrm{H}^{\delta} 7.319 / \mathrm{H}^{\varepsilon} 7.221 / \mathrm{H}^{\chi} 7.273$ \\
\hline Leu13 & 8.295 & 4.346 & $1.928 / 1.622$ & 1.830 & $\mathrm{H}^{\delta} 0.97$ \\
\hline Pro14 & & 4.360 & $2.427 / 1.864$ & 2.212 & $\mathrm{H}^{\delta} 3.812 / 3.501$ \\
\hline Lys15 & 7.293 & 4.220 & $2.106 / 1.982$ & 1.548 & $\mathrm{H}^{\delta} 1.689$ \\
\hline Ile16 & 7.803 & 3.934 & 2,027 & $1.652 / 1.227 / 0.963$ & $\mathrm{H}^{\delta} 0.909$ \\
\hline Phe17 & 8.480 & 4.305 & 3.222 & & $\mathrm{H}^{\delta} 7.304 / \mathrm{H}^{\varepsilon} 7.221 / \mathrm{H}^{\zeta} 7.209$ \\
\hline Cys 18 & 8.411 & 4.410 & 3.214 & & \\
\hline Lys19 & 7.945 & 4.222 & $2.168 / 2.042$ & 1.611 & $\mathrm{H}^{\delta} 1.748$ \\
\hline Ile20 & 8.280 & 3.973 & 1.964 & $1.759 / 1.344 / 0.971$ & $\mathrm{H}^{\delta} 0.896$ \\
\hline Thr21 & 7.812 & 4.196 & 4.196 & 1.021 & \\
\hline $\operatorname{Arg} 22$ & 7.845 & 4.182 & 2.230 & 1.717 & $\mathrm{H}^{\delta} 3.313$ \\
\hline Lys23 & 8.047 & 4.532 & $2.090 / 1.742$ & 1.538 & $\mathrm{H}^{\delta} 1.742$ \\
\hline Cys24 & 7.789 & 4.675 & $3.601 / 3.298$ & & \\
\hline
\end{tabular}

n.d. ${ }^{\text {a }}$, not detected.

helical structure only in peptides with a tendency toward helix formation [16,20,44]. Since the secondary structure of Brevinin 1E in a $60 \%$ TFE/water solution is similar to that in DPC micelles (Fig. 2), the three-dimensional structure of Brevinin 1E was calculated in 60\% TFE solution.

The conformational behaviors of Brevinin 1E in aqueous buffer, the TFE/water solutions and in dodecylphosphocholine (DPC) micelles were investigated by using CD spectroscopy (Fig. 2). From the $\mathrm{CD}$ spectra of Brevinin $1 \mathrm{E}$ in aqueous buffer, it was found that Brevinin 1E has no regular secondary structure. However, in the presence of membrane mimetics such as TFE/water solution and DPC micelles, the CD spectra of Brevinin 1E showed two minima at 208 and $222 \mathrm{~nm}$ and a cross-over point at about $200 \mathrm{~nm}$, which are characteristic of the presence of a highly $\alpha$-helical conformation. The helix content increased upon increasing TFE and detergent concentration, and then maximal helix content was reached at $60 \%$ TFE and $5 \mathrm{mM}$ DPC micelles, respectively. The helix contents in $60 \%$ TFE solution and $5 \mathrm{mM}$ DPC micelles were estimated to be about $49.1 \%$ and $77.3 \%$, respectively. These results indicate that the helicity of the Brevinin $1 \mathrm{E}$ increased in micellar environments. This conformational transition of Brevinin 1E from random-coil in aqueous solution to $\alpha$-helix in membrane-mimetic environments reflects its potentiality of interaction with membrane.

The helical structure of Brevinin 1E in TFE/water solution was precisely investigated on the basis of the NOE data. The short and medium interresidue NOE cross-peaks identified in this study and $\mathrm{d}_{\mathrm{NN}}(i, i+1)$ cross-peaks are presented in Fig. 3. In Brevinin 1E, the intramolecualr disulfide bond between Cys18 and 
Table 4

Structural statistics for Brevinin IE

\begin{tabular}{|c|c|}
\hline Structural statistics & $\langle\mathrm{SA}\rangle^{\mathrm{a}}$ \\
\hline \multicolumn{2}{|l|}{ R.m.s deviation $(\AA)$ with respect to mean } \\
\hline \multicolumn{2}{|l|}{ Whole residues } \\
\hline Heavy backbone atoms & $1.23 \pm 0.46$ \\
\hline All heavy atoms & $2.09 \pm 0.47$ \\
\hline \multicolumn{2}{|l|}{ Residues 6-17 (helix region) } \\
\hline Heavy backbone atoms & $0.52+0.18$ \\
\hline All heavy atoms & $1.10 \pm 0.19$ \\
\hline R.m.s deviation from experimental distance restraints $(\AA)(291)$ & $0.0082 \pm 0.0005$ \\
\hline R.m.s deviation from backbone torsion angle restraints $\left({ }^{\circ}\right)^{\mathrm{c}}(15 \phi)$ & $0.0418 \pm 0.0220$ \\
\hline \multicolumn{2}{|l|}{ R.m.s deviation from idealized geometry } \\
\hline Bonds $(\AA)$ & $0.0011 \pm 0.00005$ \\
\hline Angles $\left({ }^{\circ}\right)$ & $0.3925 \pm 10.0017$ \\
\hline Impropers $\left({ }^{\circ}\right)$ & $0.1127 \pm 0.0038$ \\
\hline \multicolumn{2}{|l|}{ Measures of structure quality } \\
\hline \multicolumn{2}{|l|}{ Final energies $\left(\mathrm{kcal} \mathrm{mol}^{-1}\right)$} \\
\hline$E_{\text {total }}$ & $24.75 \pm 0.35$ \\
\hline$E_{\text {bond }}$ & $0.50 \pm 0.05$ \\
\hline$E_{\text {angle }}$ & $17.46 \pm 0.15$ \\
\hline$E_{\text {improper }}$ & $0.39 \pm 0.03$ \\
\hline$E_{\mathrm{VDW}}$ & $4.93 \pm 0.30$ \\
\hline$E_{\mathrm{NOE}}$ & $1.46 \pm 0.16$ \\
\hline \multicolumn{2}{|l|}{ PROCHECK analysis } \\
\hline \multicolumn{2}{|l|}{ Ramachandran analysis (30 structures) } \\
\hline Most favored regions from Ramachandran plot (\%) & 80.4 \\
\hline Additionally favored regions from Ramachandran plot (\%) & 19.6 \\
\hline Generously favored regions from Ramachandran plot (\%) & 0 \\
\hline Disallowed regions from Ramachandran plot (\%) & 0 \\
\hline
\end{tabular}

${ }^{a}\langle\mathrm{SA}\rangle$ are the final 30 simulated annealing structures.

${ }^{\mathrm{b}}$ None of the $\langle\mathrm{SA}\rangle$ structures exhibited distance violations $>0.3 \AA$.

${ }^{\mathrm{c}}$ The backbone torsion angle $(\phi)$ restraints were derived from DQF-COSY spectra.

Cys 24 could be inferred from the presence of the NOE cross-peaks of Cys $18_{\mathrm{H} \beta}-\mathrm{Cys} 24_{\mathrm{H} \beta}, \mathrm{Cys}_{1} 8_{\mathrm{NH}^{-}}$ Cys $24_{\mathrm{H} \beta}, \mathrm{Cys} 18_{\mathrm{H} \alpha}-\mathrm{Cys} 24_{\mathrm{H} \beta}, \mathrm{Cys} 18_{\mathrm{H} \beta}-\mathrm{Cys} 24_{\mathrm{H} \alpha}$ and $\mathrm{Cys} 18_{\mathrm{H} \beta}-\mathrm{Cys} 24_{\mathrm{HN}}$. These results revealed that Brevinin 1E is composed of an $\alpha$-helix like other antimicrobial peptides from Ranidae such as ranalexin [14] with high sequence homology.

\subsection{Three-dimensional structure}

The complete assignment of the ${ }^{1} \mathrm{H}$ resonances is given in Table 3. Total 291 distance restraints and 15 backbone dihedral angle restraints were used for calculating the structure of Brevinin 1E in TFE/water solution. No hydrogen bond restraints were used because of their fast amide proton exchange rate. Simulated annealing (SA) calculations were run to produce structures with a common fold that were in good agreement with the experimental restraints and had low total energies. Out of 200 structures, 165 structures with no distance violation larger than $0.5 \AA$ and no dihedral violation larger than $5^{\circ}$ were selected. Then, the 30 structures with the lowest energies were chosen to represent the solution structure 

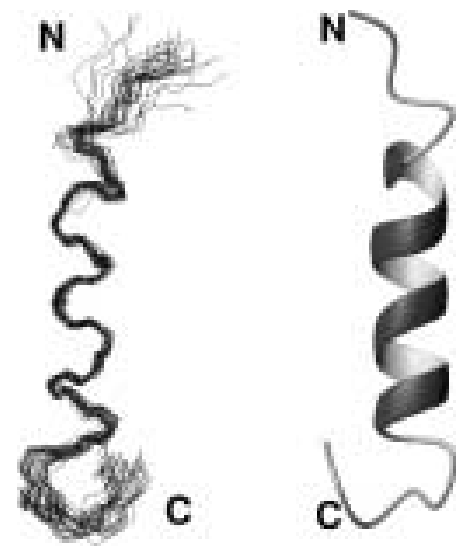

Fig. 4. Superimposition of the backbone atoms (N, C $\alpha$, and $\left.\mathrm{C}^{\prime}\right)$ of 30 structures (left). The structures of Brevinin $1 \mathrm{E}$ were aligned for the best overlap of residues 6 to 17. The ribbon presentation of average structure is shown (right). The top of structures exhibits flexible $\mathrm{N}$-terminal region.
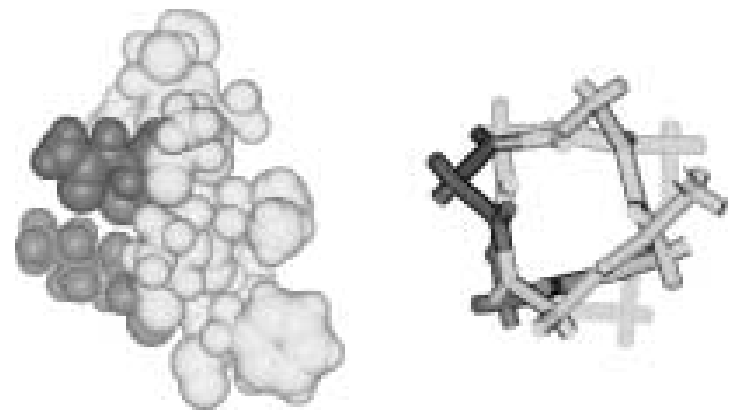

Fig. 5. Backbone and side chains of residues 6-17 are shown as a conic presentation (left). Residues 6-17 are showed as a neon presentation (right). Hydrophobic and hydrophilic residues are indicated as light and dark gray, respectively. The direction of view is perpendicular (left) and parallel (right) to the helical axis, respectively.

of Brevinin 1E (Table 4). As shown, the structure is depicted by one locally well-defined helix, which is composed of residues 6 to 17 (Fig. 4). The convergence of C-terminal conformation in Brevinin 1E reveals the formation of intraresidue disulfide bridge between Cys18 and Cys24. The overall structural feature of Brevinin $1 \mathrm{E}$ is similar to that of magainin and nigrocin (Fig. 6). Structural statistics for the mean and 30 converged structures were evaluated in terms of structural parameters, as shown in Table 4. In Brevinin 1E, the 30 final converged structures exhibited an RMSD about the mean coordinate positions for residues $1-24$ being $1.23 \AA$ for the backbone atoms $\left(\mathrm{N}, \mathrm{C} \alpha, \mathrm{C}^{\prime}\right)$ and $2.09 \AA$ for all heavy atoms. The high value of RMSD of whole structures is due to the flexible terminal region (Fig. 4). On the other hand, the helix from residues 6 to 17 have well defined structures, with average RMSDs of $0.52 \AA$ for the backbone atoms. Therefore, Brevinin 1E has well defined linear $\alpha$-helix spanning residues 6-17 (Fig. 4). The backbones of the $\mathrm{N}$ - and C-terminal are poorly defined in TFE/water solution, being probably due to some flexibility of this region. The $\mathrm{N}$-terminal region may be involved in the interaction with membrane through the hydrophobic residues (L2), which may play the similar role like F1 and L2 of ranalexin [14]. Amide protons were exchanged fast in TFE/water solution. These results are probably due to the looseness of $\alpha$-helical conformation in the experiment conditions. The three-dimensional fold of Brevinin 1E is generally amphipathic in the helix region (Fig. 5). This typical amphipathic helix has been thought to 

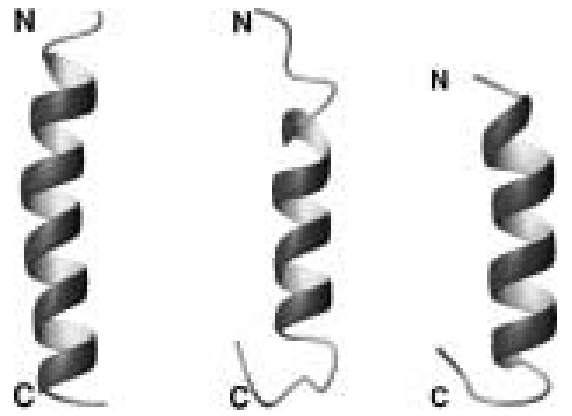

Fig. 6. Structure comparison of of Brevinin 1E (middle) with magainin (left) and nigrocin 2 (right).

be important for the antimicrobial activity $[1,8,13,25,32,34,36-38]$. In many cases, the amphipathic nature of $\alpha$-helical peptide is known to be important for membrane binding [17,21,41,45]. The amphipathic feature of Brevinin 1E is expected to mediate the interaction with microbial membranes, ultimately leading to disruption of membrane integrity. These results suggest that the overall three-dimensional fold of Brevinin 1E is similar to those of other antimicrobial peptides of about 20 residues length from Ranidae, and therefore they may have a similar action mechanism at the structural level.

\section{Conclusion}

The first solution structure of Brevinin 1E in 60\% TFE/water solution was determined and the amphipatic helix motif of Brevinin $1 \mathrm{E}$ is similar to those found in many antimicrobial peptides from frog. It could be concluded that Brevinin $1 \mathrm{E}$ is classified into the family of antimicrobial peptides containing a single linear amphipathic $\alpha$-helix that interact with target microbial membrane, leading to cell death through disruption of membrane integrity.

\section{Acknowledgements}

This work was supported by Grants (HMP-00-CH-15-0014) from the Ministry of Health and Welfare, Republic of Korea. This work was also supported in part by 2002 BK21 project for Medicine, Dentistry, and Pharmacy.

\section{References}

[1] A. Mor, V.H. Nguyen, A. Delfour, D. Migliore-Samour and P. Nicolas, Isolation, amino acid sequence, and synthesis of dermaseptin, a novel antimicrobial peptide of amphibian skin, Biochemistry 30 (1991), 8824-8830.

[2] A.T. Brünger, P.D. Adamsb, G.M. Clore, W.L. DeLanod, P. Grose, R.W. Grosse-Kunstlevea, J. Jiang, J. Kuszewskic, M. Nilges, N.S. Pannu, R.J. Read, L.M. Rice, T. Simonson and G.L. Warren, Crystallography \& NMR system: A new software suite for macromolecular structure determination, Acta Cryst. D 54 (1998), 905-921.

[3] B. Bechinger, L.M. Gierasch, M. Montal, M. Zasloff and S.J. Opella, Orientations of helical peptides in membrane bilayers by solid state NMR spectroscopy, Solid State Nucl. Magn. Reson. 7 (1996), 185-191.

[4] B. Bechinger, M. Zasloff and S.J. Opella, Structure and dynamics of the antibiotic peptide PGLa in membranes by solution and solid-state nuclear magnetic resonance spectroscopy, Biophys. J. 74 (1998), 981-987.

[5] B. Bechinger, M. Zasloff and S.J. Opella, Structure and interactions of magainin antibiotic peptides in lipid bilayers: a solid-state nuclear magnetic resonance investigation, Biophys. J. 62 (1992), 12-24. 
[6] B. Bechinger, M. Zasloff and S.J. Opella, Structure and orientation of the antibiotic peptide magainin in membranes by solid-state nuclear magnetic resonance spectroscopy, Protein Sci. 2 (1993), 2077-2084.

[7] B.D. Davis, R. Dulbecco, H.N. Eisen, H.S. Ginsberg, W.B. Wood and M. McCarty, Microbiology, 2nd edn, Harper \& Row, Hagerstown, MD, 1973.

[8] B.W. Gibson, D.Z. Tang, R. Mandrell, M. Kelly and E.R. Spindel, Bombinin-like peptides with antimicrobial activity from skin secretions of the Asian toad Bombina orientalis, J. Biol. Chem. 266 (1991), 23 103-23 111.

[9] C.L. Moberg and Z.A. Cohn, Launching the Antibiotic Era. Personal Accounts of the Discovery and Use of the First Antibiotics, Rockefeller University Press, New York, 1990.

[10] D. Barra and M. Simmaco, Amphibian skin: a promising resource for antimicrobial peptides, Trends Biotechnol. 13 (1995), 205-209.

[11] D. Marion, M. Zasloff and A. Bax, A two-dimensional NMR study of the antimicrobial peptide magainin 2, FEBS Lett. 227 (1988), 21-26.

[12] D. Marion, P.C. Driscoll, L.E. Kay, P.T. Wingfield, A. Bax, A.M. Gronenborn and G.M. Clore, Overcoming the overlap problem in the assignment of ${ }^{1} \mathrm{H}$ NMR spectra of larger proteins by use of three-dimensional heteronuclear ${ }^{1} \mathrm{H}_{-}{ }^{15} \mathrm{~N}$ Hartmann-Hahn-multiple quantum coherence and nuclear Overhauser-multiple quantum coherence spectroscopy: application to interleukin 1 beta, Biochemistry 28 (1989), 6150-6156.

[13] D.P. Clark, S. Durell, W.L. Maloy and M. Zasloff, Ranalexin: A novel antimicrobial peptide from bullfrog (Rana catesbeiana) skin, structurally related to the bacterial antibiotic, polymyxin, J. Biol. Chem. 269 (1994), 10849-10 855.

[14] E. Vignal, A. Chavanieu, P. Roch, L. Chiche, G. Grassy, B. Calas and A. Aumelas, Solution structure of the antimicrobial peptide ranalexin and a study of its interaction with perdeuterated dodecylphosphocholine micelles, Eur. J. Biochem. 253 (1998), 221-228.

[15] F. Delaglio, S. Grzesiek, G. Vuister, G. Zhu, J. Pfeifer and A. Bax, NMRPipe: a multidimensional spectral processing system based on UNIX pipes, J. Biomol. NMR 6 (1995), 277-293.

[16] F.D. Sönnichsen, J.E. Van Eyk, R.S. Hodges and B.D. Sykes, Effect of trifluoroethanol on protein secondary structure: an NMR and CD study using a synthetic actin peptide, Biochemistry 31 (1992), 8790-8798.

[17] G.E. Gilbert and J.D. Baleja, Membrane-binding peptide from the $\mathrm{C} 2$ domain of factor VIII forms an amphipathic structure as determined by NMR spectroscopy, Biochemistry 34 (1995), 3022-3031.

[18] G.S. Yi, C.B. Park, S.C. Kim and C. Cheong, Solution structure of an antimicrobial peptide buforin II, FEBS Lett. 398 (1996), 87-90.

[19] H.G. Boman and D. Hultmark, Cell-free immunity in insects, Annu. Rev. Microbiol. 41 (1987), 103-126.

[20] H.J. Dyson, G. Merutka, J.P. Waltho, R.A. Lerner, and P.E. Wright, Folding of peptide fragments comprising the complete sequence of proteins. Models for initiation of protein folding. I. Myohemerythrin, J. Mol. Biol. 226 (1992), 795-817.

[21] H.L.J. Wienk, M. Czisch and B. Kruijff, The structural flexibility of the preferredoxin transit peptide, FEBS Lett. 453 (1999), 318-326.

[22] H. Wong, J.H. Bowie and J.A. Carver, The solution structure and activity of caerin 1.1, an antimicrobial peptide from the Australian green tree frog, Litoria splendida, Eur. J. Biochem. 247 (1997), 545-557.

[23] J.E. Gabay, Ubiquitous natural antibiotics, Science 264 (1994), 373-374.

[24] J. Gesell, M. Zasloff and S.J. Opella, Two-dimensional ${ }^{1}$ H NMR experiments show that the 23-residue magainin antibiotic peptide is an alpha-helix in dodecylphosphocholine micelles, sodium dodecylsulfate micelles, and trifluoroethanol/water solution, J. Biomol. NMR 9 (1997), 127-135.

[25] J.M. Park, J.E. Jung and B.J. Lee, Antimicrobial peptides from the skin of a Korean frog, Rana rugosa, Biochem. Biophys.Res. Commun. 205 (1994), 948-954.

[26] J.Y. Suh, K.H. Lee, S.W. Chi, S.Y. Hong, B.W. Choi, H.M. Moon and B.S. Choi, Unusually stable helical kink in the antimicrobial peptide - a derivative of gaegurin, FEBS Lett. 392 (1996), 309-312.

[27] K. Wüthirch, M. Billerter and W. Braun, Pseudo-structures for the 20 common amino acids for use in studies of protein conformations by measurements of intramolecular proton-proton distance constraints with nuclear magnetic resonance, J. Mol. Biol. 169 (1983), 949-961.

[28] K. Wüthrich, NMR of Protein and Nucleic Acids, John Wiley and Sons, New York, 1986.

[29] M. Billeter, W. Braun and K. Wüthrich, Sequential resonance assignments in protein ${ }^{1} \mathrm{H}$ nuclear magnetic resonance spectra. Computation of sterically allowed proton-proton distances and statistical analysis of proton-proton distances in single crystal protein conformations, J. Mol. Biol. 155 (1982), 321-346.

[30] M. Nilges, A.M. Gronenborn, A.T. Brünger and G.M. Clore, Determination of three-dimensional structures of proteins by simulated annealing with interproton distance restraints. Application to crambin, potato carboxypeptidase inhibitor and barley serine proteinase inhibitor 2, Protein Eng. 2 (1988), 27-38.

[31] M. Piotto, V. Saudek and V. Sklenar, Gradient-tailored excitation for single-quantum NMR spectroscopy of aqueous solutions, J. Biomol. NMR 2 (1992), 661-665.

[32] M. Simmaco, D. Barra, F. Chiarini, L. Noviello, P. Melchiorri, G. Kreil and K. Richter, A family of bombinin-related peptides from the skin of Bombina variegate, Eur. J. Biochem. 199 (1991), 217-222. 
[33] M. Simmaco, G. Mignogna, D. Barra and F. Bossa, Antimicrobial peptides from skin secretions of Rana esculenta. Molecular cloning of cDNAs encoding esculentin and brevinins and isolation of new active peptides, J. Biol. Chem. 269 (1994), 11 956-11961.

[34] M. Simmaco, G. Mignogna, D. Barra and F. Bossa, Novel antimicrobial peptides from skin secretion of the European frog Rana esculenta, FEBS Lett. 324 (1993), 159-161.

[35] M.Y. Kwon, S.Y. Hong and K.H. Lee, Structure-activity analysis of brevinin 1E amide, an antimicrobial peptide from Rana esculenta, Biochim. Biophys. Acta 1387 (1998), 239-248.

[36] M. Zasloff, Magainins, a class of antimicrobial peptides from Xenopus skin: isolation, characterization of two active forms, and partial cDNA sequence of a precursor, Proc. Natl. Acad. Sci. USA 84 (1987), 5449-5453.

[37] N. Morikawa, K. Hagiwara and T. Nakajima, Brevinin-1 and -2, unique antimicrobial peptides from the skin of the frog, Rana brevipoda porsa, Biochem. Biophys. Res. Commun. 189 (1992), 184-190.

[38] P. Nicolas and A. Mor, Peptides as weapons against microorganisms in the chemical defense system of vertebrates, Annu. Rev. Microbiol. 49 (1995), 277-304.

[39] R.A. Laskowski, J.A. Rullmannn, M.W. MacArthur, R. Kaptein and J.M. Thornton, AQUA and PROCHECK-NMR: programs for checking the quality of protein structures solved by NMR, J. Biomol. NMR 8 (1996), 477-486.

[40] R.I. Lehrer, T. Ganz and M.E. Selsted, Defensins: endogenous antibiotic peptides of animal cells, Cell 64 (1991), 229-230.

[41] R. Pfänder, L. Neumann, M. Zweckstetter, C. Seger, T.A. Holak and R. Tampé, Structure of the active domain of the herpes simplex virus protein ICP47 in water/sodium dodecyl sulfate solution determined by nuclear magnetic resonance spectroscopy, Biochemistry 38 (1999), 13 692-13 698.

[42] S.H. Park, S.-H. Park, H.C. Ahn, S.K. Kim, S.S. Kim, B.-J. Lee and B.J. Lee, Structural study of novel antimicrobial peptides, nigrocins, isolated from Rana nigromaculata, FEBS Lett. 507 (2001), 95-100.

[43] S.H. Park, Y.K. Kim, J.W. Park, B. Lee and B.J. Lee, Solution structure of the antimicrobial peptide gaegurin 4 by $1 \mathrm{H}$ and $15 \mathrm{~N}$ nuclear magnetic resonance spectroscopy, Eur. J. Biochem. 267 (2000), 2695-2704.

[44] S. Segawa, T. Fukuno, K. Fujiwara and Y. Noda, Local structures in unfolded lysozyme and correlation with secondary structures in the native conformation: helix-forming or -breaking propensity of peptide segments, Bioploymers 31 (1991), 497-509.

[45] V. Wray, D. Mertins, M. Kiess, P. Henklein, W. Trowizsch-Kienast and U. Schubert, Solution structure of the cytoplasmic domain of the human CD4 glycoprotein by CD and ${ }^{1} \mathrm{H}$ NMR spectroscopy: implications for biological functions, Biochemistry 37 (1998), 8527-8538.

[46] W.L. Maloy and U.P. Kari, Structure-activity studies on magainins and other host defense peptides, Biopolymers (Pept. Sci.) 37 (1995), 105-122.

[47] Y.H. Chen, J.T. Yang and H.M. Martinez, Determination of the secondary structures of proteins by circular dichroism and optical rotatory dispersion, Biochemistry 11 (1972), 4120-4131. 


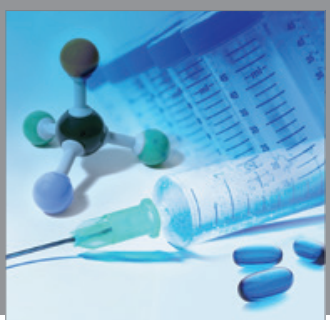

International Journal of

Medicinal Chemistry

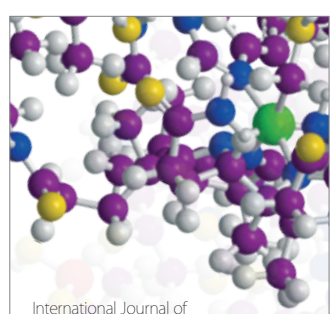

Carbohydrate Chemistry

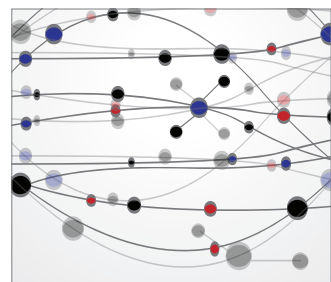

The Scientific World Journal
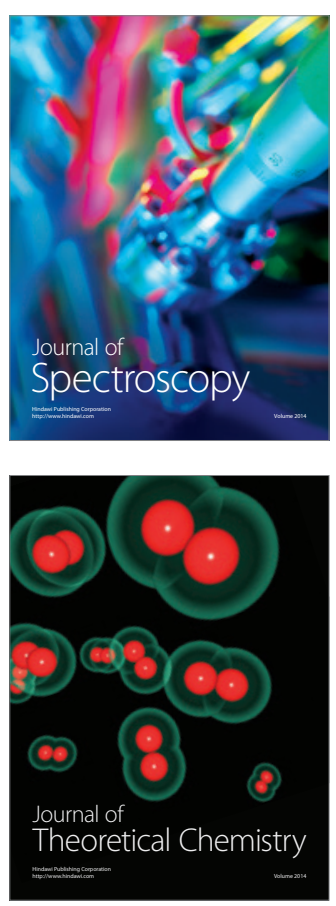
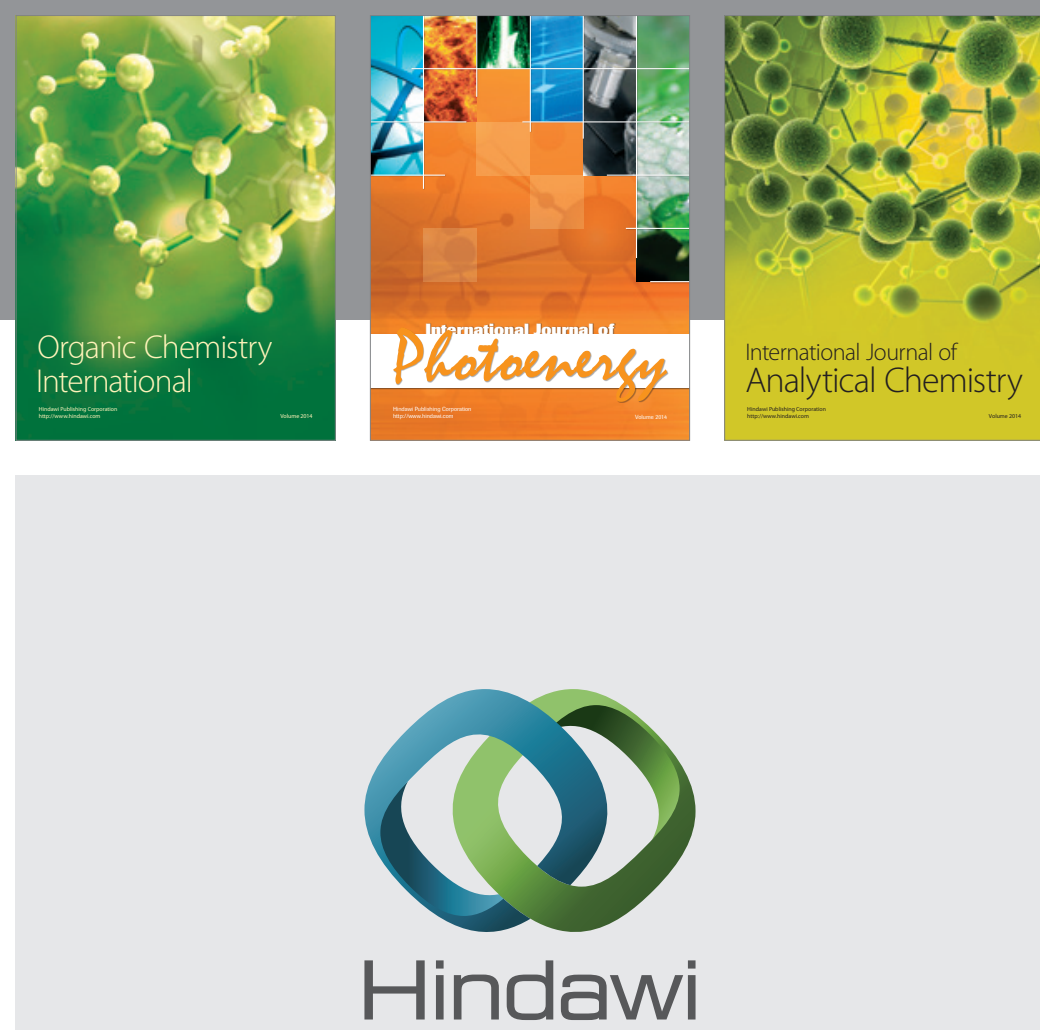

Submit your manuscripts at

http://www.hindawi.com
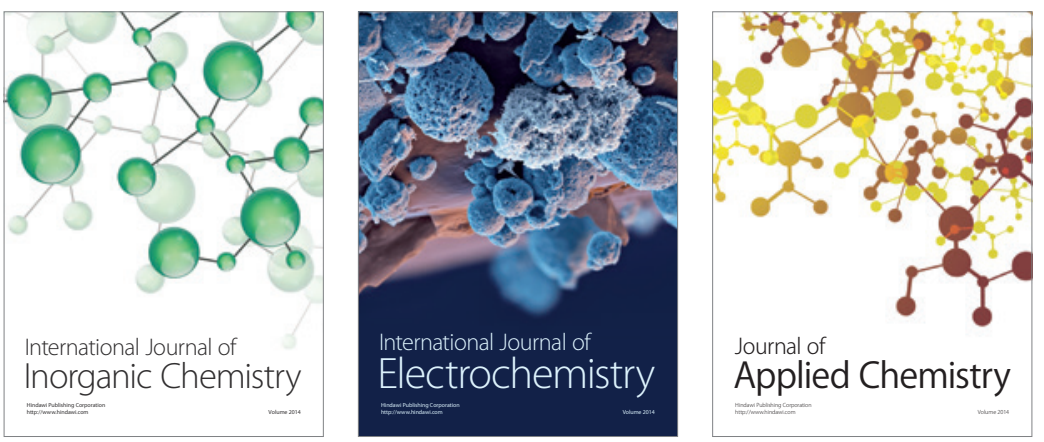

Journal of

Applied Chemistry
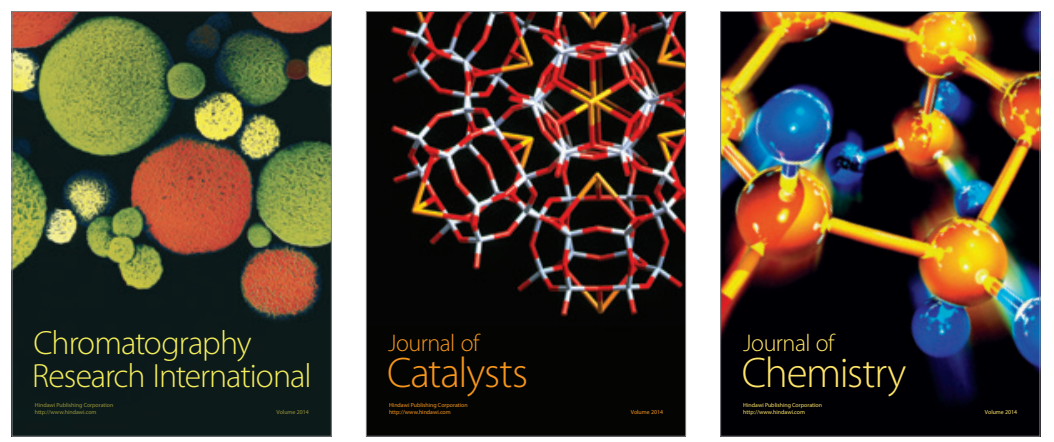
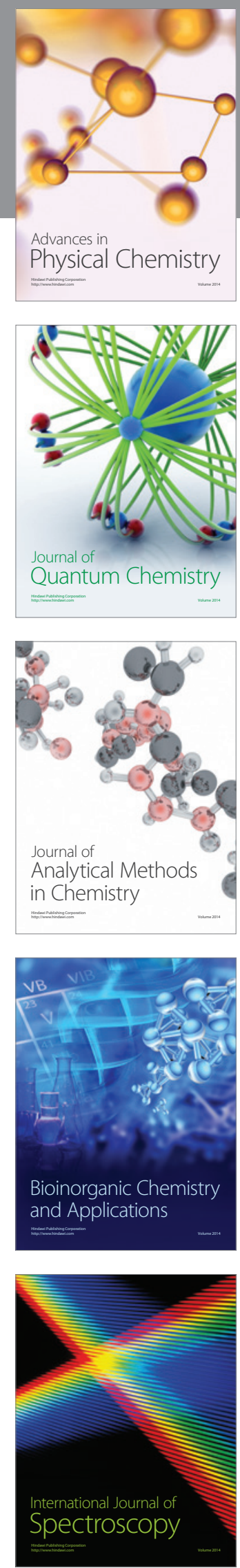